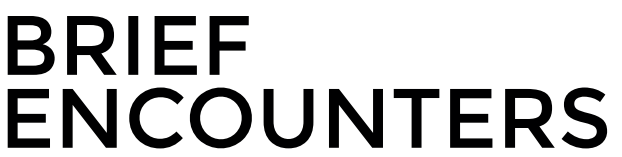

ISSN: 2514-0612

Journal homepage: http://briefencounters-journal.co.uk/BE

Alternative Photography as an Ethnographic Method

Author(s): Flora Mary Bartlett

Email: flora.bartlett@gold.ac.uk

Source: Brief Encounters, Vol. 2 No. 1 (Jan 2018), pp. 93-102.

URL: http://briefencounters-journal.co.uk/BE/article/view/104

DOI: http://dx.doi.org/10.24134/be.v2i1.104

(c) Flora Mary Bartlett

License (open-access): This is an open-access article distributed under the terms of the

Creative Commons Attribution License 4.0, which permits unrestricted use, distribution, and reproduction in any medium, provided the original work is properly cited. No warranty, express or implied, is given. Nor is any representation made that the contents will be complete or accurate or up to date. The publisher shall not be liable for any actions, claims, proceedings, demand or costs or damages whatsoever or howsoever caused arising directly or indirectly in connection with or arising out of the use of this material. 


\title{
Alternative Photography as an Ethnographic Method
}

\author{
Flora Mary Bartlett
}

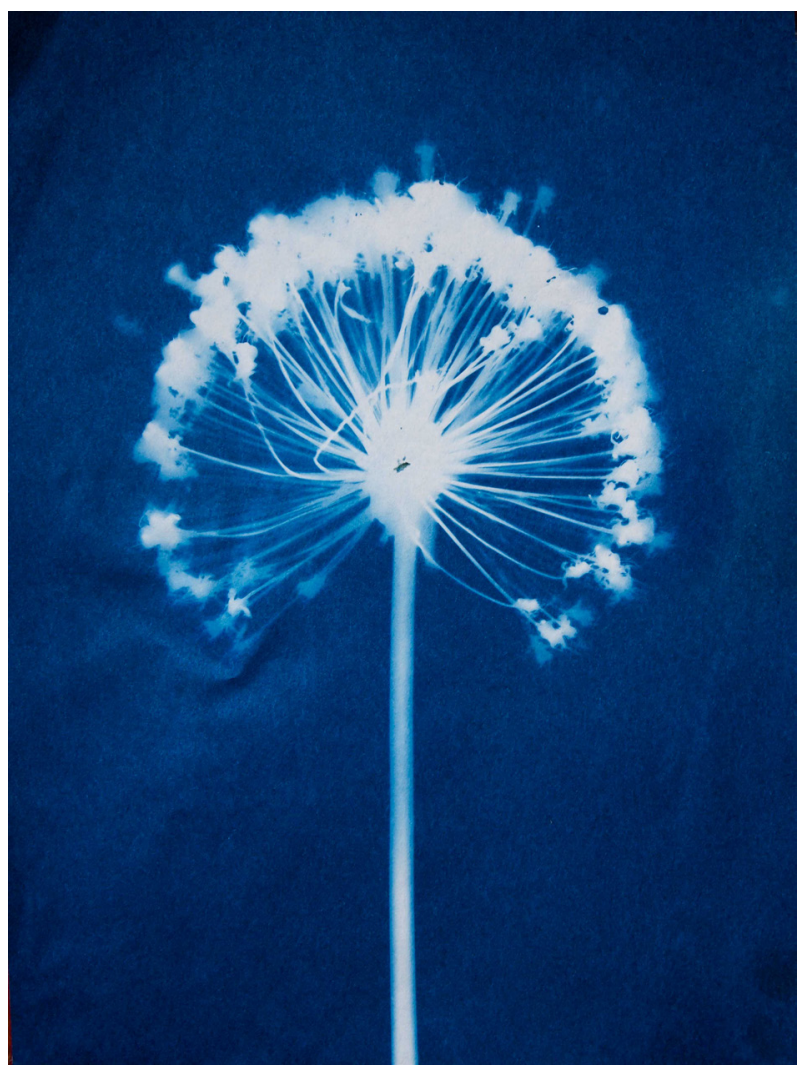

Figure 1

Anthropology has a contentious history with photography. Early examples illustrated written texts with classificatory images of racial types, with sitters posed against backdrops that measured and objectified them. As such, they were 'embedded in the power relations of imperialism' and continued the 'objectifying gaze of the colonial project'. Subsequently, images were neglected as the discipline went through something of an identity crisis, and images were seen as entangled within this problematic past. ${ }^{2}$ In the last 50 years, however, some anthropologists have become increasingly aware of the creative potential of using visual methods ethically and collaboratively in their research.

\footnotetext{
Sarah Pink, Doing Visual Ethnography (London: Sage, 2009), p. 7.

2 Marcus Banks and Howard Morphy, 'Introduction: Rethinking Visual Anthropology', in Rethinking Visual Anthropology, ed. by Marcus Banks and Howard Morphy (New Haven and London: Yale University Press, 1997), pp.1-54; For a comprehensive look at the dual histories of anthropology and photography, see Christopher Pinney, Anthropology and Photography (London: Reaktion Books, 2011).
} 
Despite these developments, there is still a lamentable reliance on the documentary style of filmmaking: seen as the form closely associated with anthropology's main method, participant observation, it was thus perceived as the legitimate visual method in fieldwork. ${ }^{3}$ Ravetz found this method lacking in her own research as it failed to portray the imagination of her participants. Art, she argues, can show the 'unreality', the 'power of imagination' and the 'untruth'. ${ }^{4}$

Like Ravetz, I find something lacking in the use of photographs within anthropology. As with ethnographic film, the assumption remains that the documentary style of photography somehow presents the world as it is. It is seen as an objective truth of something witnessed, then placed among the words of a monograph as something of secondary importance.

As a critique of this, and a rejection of the pretence of objectivity, I have been experimenting with alternative methods of image making. I realise that the word 'alternative' has become somewhat tarnished over the past year, and I realise, increasingly, that it is used to legitimise white supremacy and to present falsities as fact in the United States. I use it here to refer to those photographic styles that are seen in fine art practice rather than those typically seen in academic work. For instance, I am thinking specifically of styles that draw from the very first photographic experiments carried out by those who began the discipline in the nineteenth century, reinvigorated through online communities sharing 'alternative photography' techniques. ${ }^{5}$ I am mainly working with photograms, cyanotypes, re-photographing archival prints, chemigrams, salt printing, and projecting images back into the environment. For this article, I focus on the first three of these methods. All images are my own and they were early-stage experiments before I began fieldwork.

\footnotetext{
${ }^{3}$ Amanda Ravetz, 'News From Home: Reflections on Fine Art and Anthropology', in Visualizing Anthropology, ed. by Anna Grimshaw and Amanda Ravetz (Bristol: Intellect Ltd, 2005), pp. 69-80.

${ }^{4}$ Ibid., p. 77.

${ }^{5}$ See, for example, Alternative Photography, <http://www.alternativephotography.com/> [accessed 15 February 2017].
} 


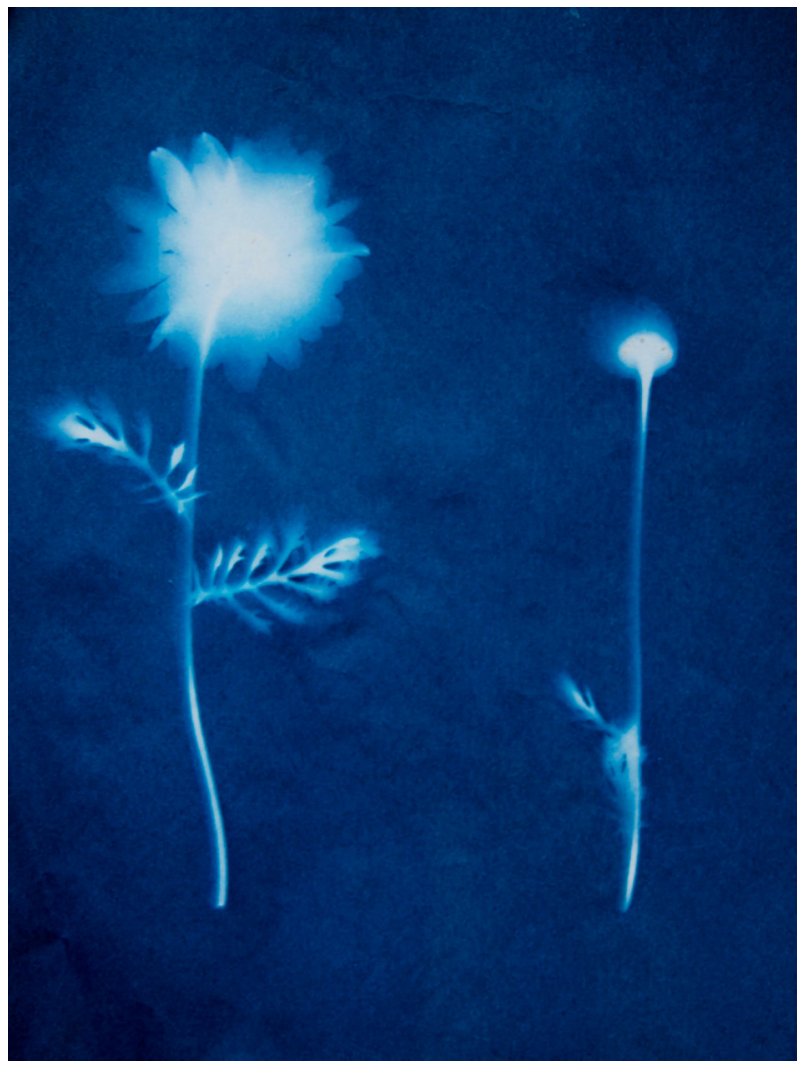

Figure 2

With these early methods, before the development of reproducible negatives, practitioners placed objects directly onto photosensitive surfaces, exposing them to light and leaving behind a trace of something real. Though they were no doubt striving for realism and progress, reproducible colour images were perhaps not yet even on their minds as a possibility.

Artists are now increasingly returning to these methods, shown in a wonderful and thorough collection in Geoffrey Batchen's book Emanations. ${ }^{6}$ The 'direct contact between us and the world' that Batchen describes of photograms is especially relevant to my own research.? I am exploring sensory experiences of climate change, and the impacts on sense of place and the environment. I will research changes in local ecology, weather and seasonal patterns, and how they are felt and discussed in Swedish Lapland. Photograms can be a way to explore ecology, to make a kind of record of organic matter that can convey more than just a direct reproduction of the object.

\footnotetext{
${ }^{6}$ Geoffrey Batchen, Emanations (Munich: DelMonico, 2016).

7 Ibid., p. 38.
} 


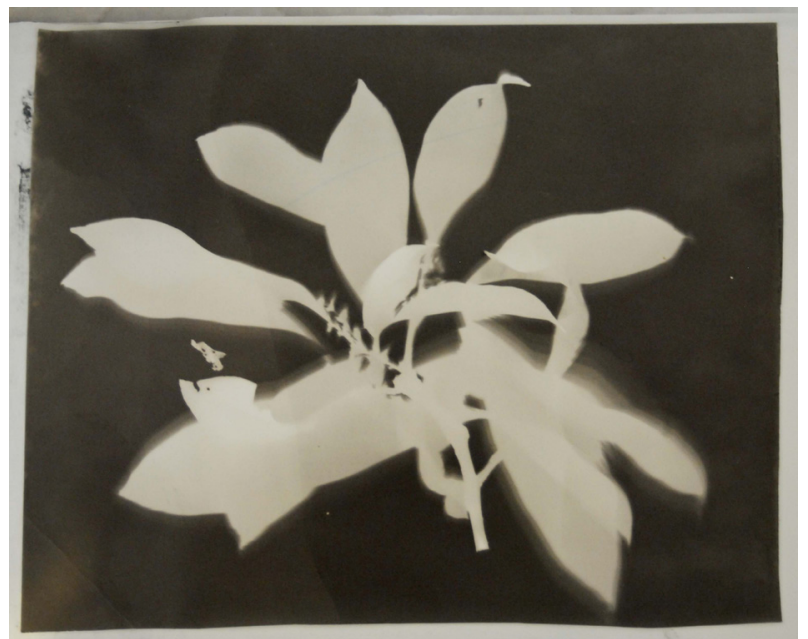

Figure 3

The above images are all photograms. Made by placing the plant directly on the photographic paper, they leave a ghostly trace of the plant's outline.

At first glance, perhaps, these images are not so helpful in anthropological endeavours. However, rather than just being a mode of dissemination, visual imagery can be a valuable methodological tool. Photographs are not only studied as material objects, but can be used actively in fieldwork in collaborative encounters with participants. Such an engagement with artistic practice forms a valuable methodology for discovering ethnographic data in the field. Artists 'learn through making', literally research through practice, while the ethnographer is classically more analytical and text based. ${ }^{8}$ Therefore, bringing the two together can form a productive harmony and provide synchronous approaches to fieldwork. Photography is not just a means to show a final concept, but a way of exploring the world and learning about ongoing processes and emotions. Furthermore, Wright and Schneider argue that there is a shared practice to art and anthropology that points to a productive interdisciplinary potential, but it must do more than serve to illustrate a written text. We need, they argue, a new and creative approach to visual methods. ${ }^{9}$

\footnotetext{
8 Roanna Heller, 'Becoming an Artist-Ethnographer', in Visualizing Anthropology, ed. by Anna Grimshaw and Amanda Ravetz (Bristol: Intellect Ltd, 2005), pp. 133- 142, p. 135.

${ }^{9}$ Chris Wright and Arnd Schneider, Contemporary Art and Anthropology (Oxford: Berg, 2006), p. 3.
} 


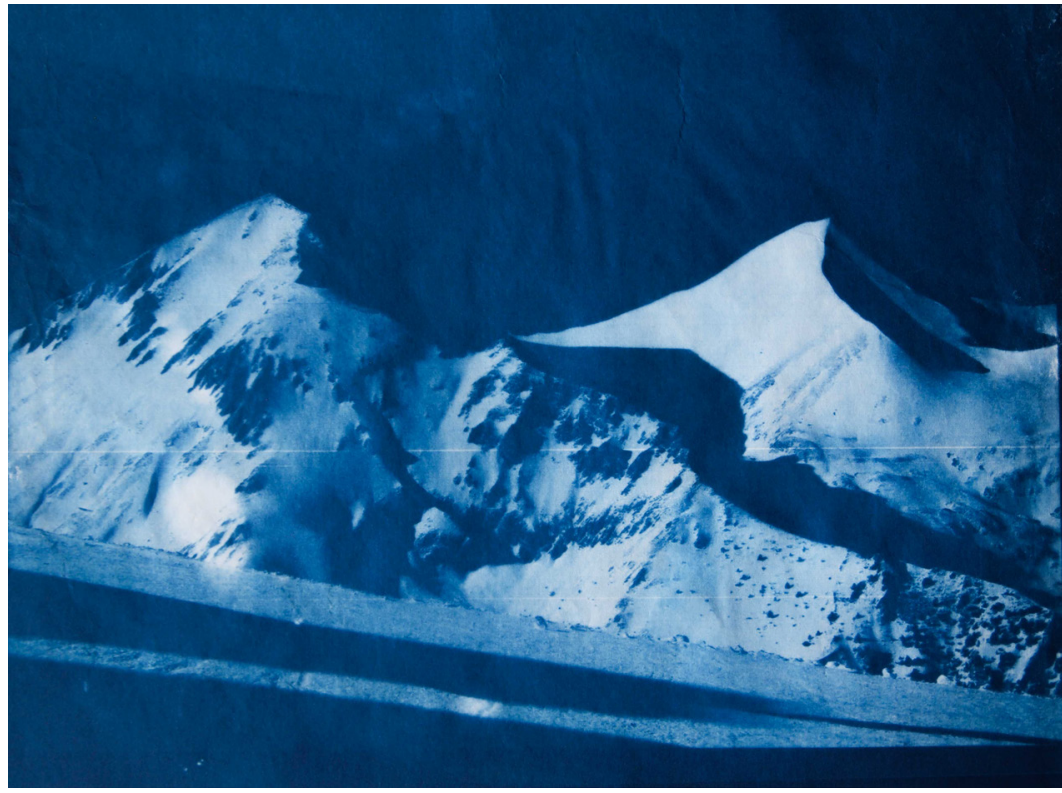

Figure 4

The blue images shown here are cyanotypes, historically used in botanical records and blueprints. The above example is a contact print made using an enlarged negative, printed onto transparency film and exposed onto the photo-sensitive cyanotype paper.

Unlike the black and white images, they do not require darkroom processing and can be made using prepared paper and rinsing in water to fix. Their distinctive colour can be a creative tool for research; for example, it can be used to emulate the 'blue hour': the colour of the Nordic sky before the sunset. As with the other photograms, they are a record of something real, but also imply something removed and non-existent. In this way, they can be a method to explore memory and affect. These images can be used with participants in the field to slow down conversations about experiences and place-making. They can be used to discuss local ecology and record traces of those that are threatened, those that are changing, or those that are new.

These images can then be part of further experimentation. Text can be drawn into the image itself using transparent labels exposed with the plant, as below, or written into the print. 


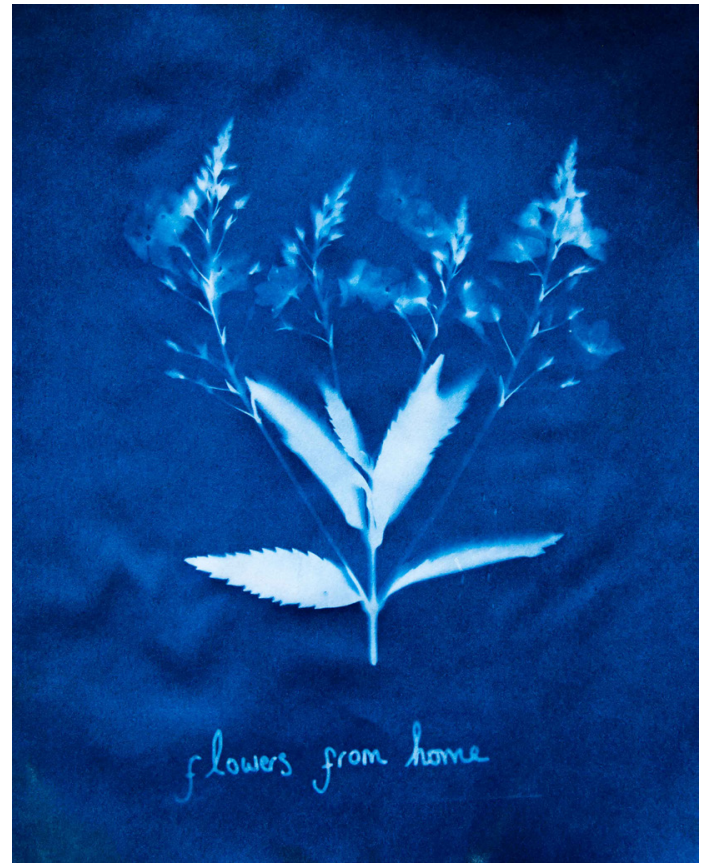

Figure 5

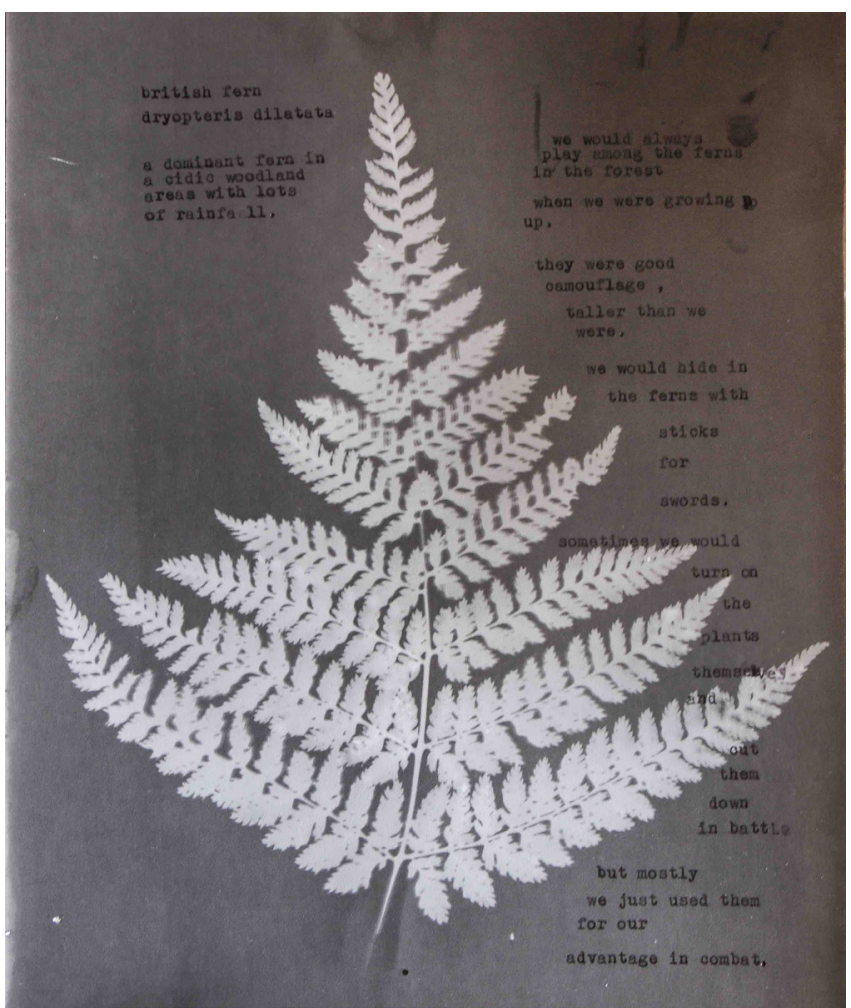

Figure 6

In the above example, I typed into the photogram with a typewriter while the image was still wet from the final darkroom rinse. This allows the text to be stamped into the image itself and not just an inky surface overlaying the paper. This is a way to play with the relationship between images and text in research, and questions the separation of the two in ethnographic writing. Rather than presenting stories 
and vignettes alongside portraits in an ethnographic monograph, this method allows the stories to be interwoven in the very substance of the image; the text is an intervention into the physical trace of the initial object.

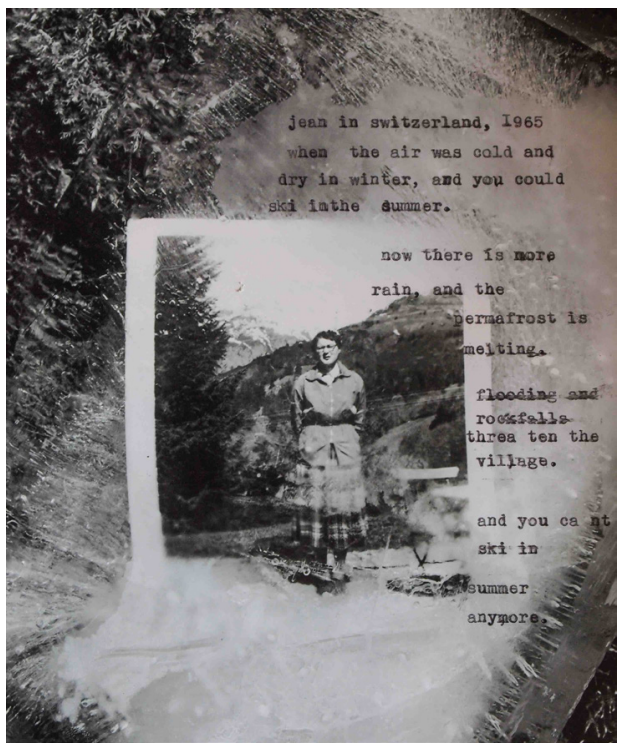

Figure 7

Above is another such example of this, using archive photography rather than photograms. I froze an old archive print of my grandmother, and re-photographed it back in the landscape, before typing into the print as before. Images are often used in photo-elicitation sessions to spark memories and contextualise events, and this is a new way to engage with pre-existing images. With the full permission of participants, images could be copied and used in such ways to instigate new conversations about experience and memory. In this way, these methods allow us to view experience as complicated and multi-faceted.

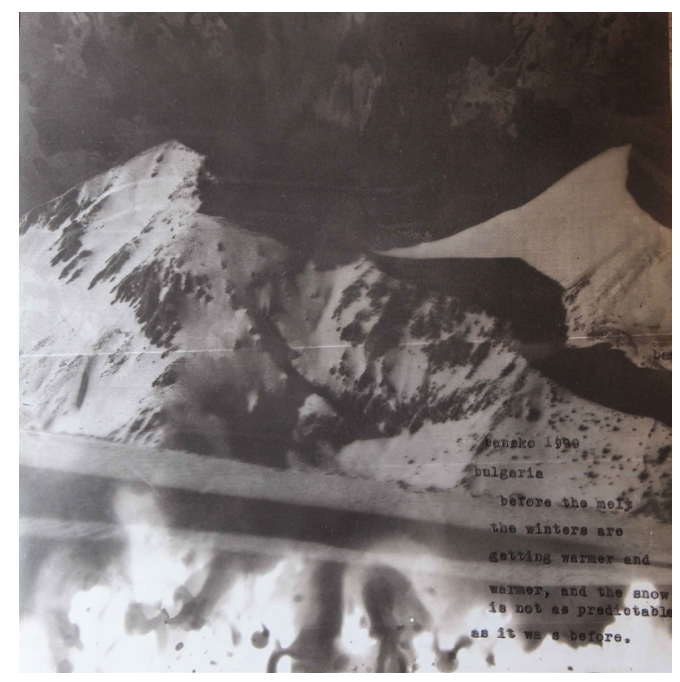

Figure 8 
In this example, a contact print was made using an enlarged negative. However, instead of submerging the print in a developer, I splashed the chemical onto the exposed paper making this mottled effect at the edges. This could be a way to play with the haziness of memory and the experience of changing landscapes.

We have inherited a strange way of perceiving experience thanks to Descartes and his binary opposition of the body and the mind: we believe ourselves to be somehow separated from the world and experiencing it only through our cognitive reflection..$^{0}$ Increasingly, scholars are arguing that this is a profoundly unhelpful way to view the world. Phenomenology is a broad philosophical approach that, while encompassing many variations, can allow for an exploration of lived experience, rather than purely conscious reflection. One branch of phenomenology that has been embraced by some anthropologists evolves from the work of Maurice Merleau-Ponty, and explores how people experience the world with their bodies through their senses in habitual, subconscious, daily engagements with their environment." Ingold has written extensively on this form of phenomenology, and asks us to view this entangled process of knowing and experiencing the environment as a 'meshwork of interwoven lines' rather than a network of separable objects. ${ }^{12}$

The methods that I have discussed, namely photograms and images overlaid with text, might be a good way of exploring and representing such 'meshworks' visually. ${ }^{13}$ They can be used to show the complexity and enmeshed reality of what it means to experience places. Furthermore, they can help to overcome the problems that Tilley argues of the 'dominance of the visual in Western culture', as they include traces of touch and can be overlaid with descriptions of multi-sensory experience. ${ }^{14}$ While they do not include the presence of the person as a direct visual representation, they include traces of the person through their choices, stories, experience and physical embodiment. The participants decide what is important in the pieces, which stories go with which objects, which old pictures, and why. Such

\footnotetext{
10 Tim Ingold, The Perception of the Environment: Essays on Livelihood, Dwelling and Skill (London and New York: Routledge, 2000), p. 165.

${ }^{11}$ Chris Tilley, The Materiality of Stone: Explorations in Landscape Phenomenology (Oxford: Berg, 2004$)$, p. 13.

12 Tim Ingold, Being Alive: Essays on Movement, Knowledge and Skill (London and New York: Routledge, 2011 ), p. 63.

13 Ibid., p. 63.

14 Tilley, p. 15.
} 
images can be creatively engaged beyond those featured here, perhaps to show movement and time in the experience of a landscape, and portray, as Ravetz called it, 'the unreality.' 15

In this article, I have argued for a use of photography that goes beyond the documentary style that claims to be a record of what the anthropologist sees in the field. I have argued for a creative engagement with the photographic processes that are as old as the discipline itself. Experimenting with photography can take many directions besides those traditional techniques listed here, with potential for multi-media work, digital processes, or putting images back into the landscape through projection and installation works. Instead of trying to show the world as it 'is', we can try and show how the world is felt and experienced by the people with whom we work. Instead of having the researcher on one side solely photographing the participants from behind a camera, the anthropologist can make these imageobjects together with participants and create new conversations around them. It is a new way, using old techniques, of utilising that which is fundamental to photography: traces of light, shaped in the pursuit of (some) understanding.

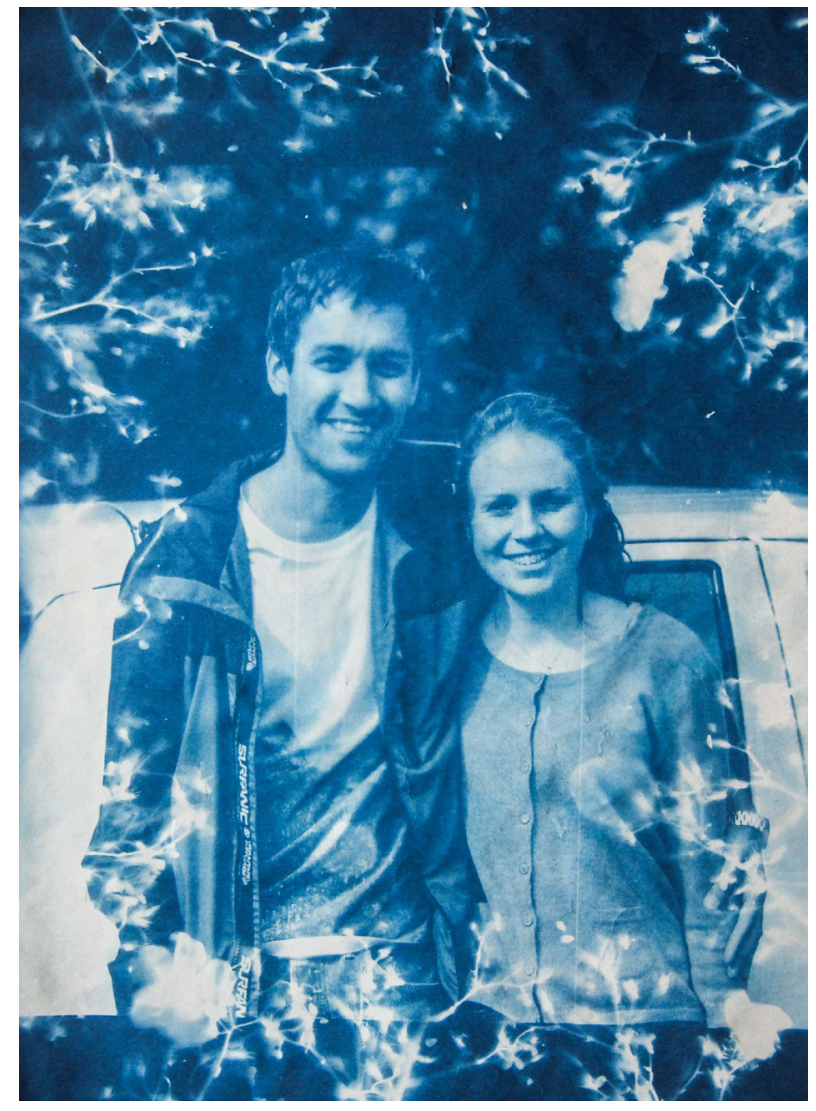

Figure 9

\footnotetext{
${ }^{15}$ Ravetz, p. 77.
} 


\section{Bibliography}

Alternative Photography, <http://www.alternativephotography.com/> [accessed 15 February 2017]

Banks, Marcus and Howard Morphy, 'Introduction: Rethinking Visual Anthropology', in Rethinking Visual Anthropology, ed. by Marcus Banks and Howard Morphy (New Haven and London: Yale University Press, 1997), pp.1-54

Batchen, Geoffrey, Emanations: The Art of the Cameraless Photograph (Munich: DelMonico, 2016)

Ingold, Tim, Being Alive: Essays on Movement, Knowledge and Skill (London: Routledge, 2011)

---, Perceptions of the Environment: Essays on Livelihood, Dwelling and Skill (London and New York: Routledge, 2000)

Heller, Roanna, 'Becoming an Artist-Ethnographer', in Visualizing Anthropology, ed. by Anna Grimshaw and Amanda Ravetz (Bristol: Intellect Ltd., 2005), pp. 133-142

Pink, Sarah, Doing Visual Ethnography (London: Sage, 2009)

Pinney, Christopher, Anthropology and Photography (London: Reaktion Books, 2011)

Ravetz, Amanda, 'News from Home: Reflections on Fine Art and Anthropology', in Visualizing Anthropology, ed. by Anna Grimshaw and Amanda Ravetz (Bristol: Intellect Ltd., 2005), pp. 69-80

Tilley, Chris, Materiality of Stone: Explorations in Landscape Phenomenology (Oxford: Berg, 2004)

Wright, Chris and Arnd Schneider, Contemporary Art and Anthropology (Oxford: Berg, 2006) 